\title{
DESIGN AND DEVELOPMENT OF A THREE-POINT AUTO HITCH DYNAMOMETER FOR AN AGRICULTURAL TRACTOR
}

\author{
A.F. Kheiralla, A. Yahya*, M. Zohadie, W. Ishak \\ Department of Biological and Agricultural Engineering, Faculty of Engineering, \\ University Putra Malaysia, 43400 Serdang, Selangor D.E., Malaysia
}

Received 10 April 2003, Accepted 3 July 2003

\begin{abstract}
This paper describes the design, development and calibration of a three-point auto hitch dynamometer for measuring the horizontal and vertical forces that existed at the three-point hitch of an agricultural tractor. The design concept of the dynamometer was based on an instrumented inverted $\mathrm{U}$ frame assembly that was mounted between tractor links and implement. The design incorporates for both lower point hitch spread and mast height adjustments, and quick hitch capability in accordance with category 1 and II three-point hitch system. The force sensing elements were comprised of three steel extended octagonal ring transducers that were located between the inverted $U$ frame and hook brackets. Electrical resistance strain gauges were mounted on the extended octagonal ring transducer at strain angle nodes to independently monitor strains that were proportional to the horizontal and vertical forces at the ring center. Each transducer was designed for maximum horizontal and vertical forces of $25 \mathrm{kN}$ and $10 \mathrm{kN}$ at measurement mean sensitivities of $25.19 \mu \mathrm{Strain} / \mathrm{kN}$ and $25.60 \mu \mathrm{Strain} / \mathrm{kN}$, respectively. However, the complete dynamometer has been designed to measure the maximum resultant horizontal and vertical forces of $50 \mathrm{kN}$ and $20 \mathrm{kN}$, respectively. Field demonstration tests on the dynamometer and data acquisition system showed that they were able to function effectively as intended. The data acquisition system was able to successfully scan and record the dynamometer signals as programmed. This dynamometer was part of the complete instrumentation system to be developed onboard a Massey Ferguson 3060 tractor for the generation of a comprehensive database on the power and energy requirements of the tractor and its working implement in the field.
\end{abstract}

\section{INTRODUCTION}

Draught and drawbar power are two pertinent performance characteristics of any agricultural implement. The availability of draught and power requirement data of tillage implements are important in selecting a suitable tillage implements for a specific farm size. Plantation managers, consultants and engineers use draught and power requirement data of a known soil type to

*Corresponding author-e-mail: azmiy@eng.upm.edu.my Tel.: +603-86567126; Fax: +603-86567099 
determine the proper size of tractor for their specific applications. Agricultural machinery contributes a major portion of the total cost of agricultural production, thus proper selection and matching of agricultural field machinery is essential in order to significantly reduce their operating costs.

Measurements of implement draughts have received prime attention in research and development of tractor instrumentation. A large number of three-point hitch dynamometers have been developed and reported by many researchers. The three-point hitch dynamometers can be generally classified into two main design configurations, namely, built-in sensor and detachable force built-in sensor. Table 1 summarised the various types of design configurations available in literature.

The tractor built-in sensor configuration has no additional frame between the tractor and the implement but has force-sensing transducers incorporated into the tractor linkage system ${ }^{1-5}$. These dynamometers do not interface with the tractor's PTO shaft and present no problems to the tractor and implement geometry. The detachable frame built-in sensor configuration can either be of single or double frame assembly types ${ }^{6-15}$. The former consists of a single frame mounted with force sensing transducers, with the frame end brackets being attached to tractor links and the transducer ends to the implements. The latter type uses two frame assemblies that are interconnected together by the force sensing transducers, with one frame being attached to the tractor links and the other frame to the implement in the manner of a quick attachment coupler. There are various types of frame and force sensing transducers that are being adopted in the design. Besides having flexibility in application, the detachable frame built-in sensor group permits easy resolution of forces into horizontal draft, vertical force, side force and their moments. In spite of that, it has the disadvantages of changing tractor and implement geometry and adding additional mass. None of the reported three-point hitches dynamometers discussed on the natural frequencies and dynamic response of their systems.

Many researchers developed their own force sensing transducers for the three-point hitch dynamometer. The extended octagonal ring has been claimed to be the most suitable and robust transducer due to its capability of independently measuring forces in two dimensions and resultant moment in one dimension. Cook et al. ${ }^{16}$, Loewen and Cook $^{17}$, and Cook and Rabinowicz ${ }^{18}$ presented generalized strain and displacement formulas and made strain nodes verifications by photoelastic determinations for octagonal extended ring. However, the detail and complete design analysis of the plain extended ring to represent that of the octagonal extended ring was not included. O'Dogherty ${ }^{19}$, Godwin ${ }^{20}$, Thakur and Godwin ${ }^{21}$, Godwin et al. ${ }^{22}$, and O'Dogherty ${ }^{23}$ used the design formulas by ${ }^{17-18}$ for the development of their octagonal extended ring transducers. Hoag and Roerger ${ }^{24}$ did a complete design analysis for the plain extended ring using strain energy techniques. They formulated formulas for determination of vertical displacements, horizontal displacements, and rotations, bending moments, shears, axial forces and other design considerations. Consequently, the strains, dimensions, natural frequencies and dynamic response of the plain extended ring transducer could be obtained. McLaughlin ${ }^{25}$ developed a double extended octagonal ring drawbar transducer for 3-D force measurement based on $^{24}$ design formulas. He concluded that analytical equations for the plain extended ring predicted horizontal draft and vertical force sensitivities of $109 \%$ and $65.5 \%$, respectively, of those obtained from 
Table 1 : Design configurations used by previous researchers

\begin{tabular}{|c|c|c|}
\hline Cat. & Researchers & Design Configurations \\
\hline 1 & Reece [1] & Strain gauges on cantilevered pins at link pivots \\
\hline 1 & Morling [2] & Strain gauges on cranked beam at link ends. \\
\hline 1 & Scholtz $[3]$ & Strain gauges on pins at linkage pivots. \\
\hline 1 & Luth et al. [4] & Strain gauges on upper lower and lift links. \\
\hline 1 & Upadhyaya et al. [5] & Strain gauges on upper lower and lift links. \\
\hline 2 & Scholtz $[6]$ & $\begin{array}{l}\text { Single inverted "U" shape frame with two "L" shaped lower sensors } \\
\text { and a "U" shaped top sensor. Allows the passage of PTO shaft. }\end{array}$ \\
\hline 2 & Johnson and Voorhees [7] & $\begin{array}{l}\text { Two inverted "T" shape frames connected by a tube-sensing element. } \\
\text { Equipped with quick attach coupler. }\end{array}$ \\
\hline 2 & Smith and Baker [8] & $\begin{array}{l}\text { Two triangular shaped frames connected by six commercial load cells. } \\
\text { Equipped with quick attach coupler. }\end{array}$ \\
\hline 2 & Chung et al. [9] & $\begin{array}{l}\text { Single inverted "U" shape frame with } 3 \text { units of cantilevered pin sensors. } \\
\text { Equipped with quick attach coupler and allows the passage for PTO } \\
\text { shaft. }\end{array}$ \\
\hline 2 & Reid et al [10] & $\begin{array}{l}\text { Single inverted "U" shape frame with } 3 \text { units of cantilevered pin sensors. } \\
\text { Allows the passage for PTO shaft. }\end{array}$ \\
\hline 2 & Chaplin et al. [11] & $\begin{array}{l}\text { Two rectangular shape frames connected by six commercial load cells. } \\
\text { Equipped with quick attach coupler. }\end{array}$ \\
\hline 2 & Garner et al. [12] & Followed Johnson and Voorhees (1979) design \\
\hline 2 & Jenane et al. [13] & Followed Chaplin et al. (1987) design \\
\hline 2 & Palmer [14] & $\begin{array}{l}\text { Two inverted "U" shape frames connected by six commercials load } \\
\text { cells. Equipped with quick attach coupler and allows the passage for } \\
\text { PTO shaft. }\end{array}$ \\
\hline 2 & McLaughlin et al. [15] & $\begin{array}{l}\text { Inverted "U" shape frame with six commercial load cells located at the } \\
\text { centre link and the two lift turnbuckles. Equipped with quick attach } \\
\text { coupler and allows the passage for PTO shaft. }\end{array}$ \\
\hline
\end{tabular}

computations. However, the application of the transducer was not meant for the three-point hitch dynamometer and aspects on the system natural frequency and dynamic response were omitted.

Research has been initiated at the Department of Biological and Agricultural Engineering, Universiti Putra Malaysia to develop an instrumentation and data acquisition system on-board a Massey Ferguson 3060 tractor for comprehensive information on the performance of the tractor and its working implement in the field. The intended system would have the capacity of measuring and monitoring engine speed, PTO speed, forward speed, drive wheel slippage, areas worked, fuel consumption per hour, fuel consumption per hectare, areas per hour, cost factor, fuel consumed, fuel remaining, and distance, and also at the same time have the capacity of measuring and recording horizontal pull at the tractor drawbar, wheel torque at both tractor rear wheels, PTO torque at the tractor PTO output, and both horizontal and vertical forces at the point hitches ${ }^{26}$.. Extensive field-testing would be conducted with this instrumented tractor on the aspects of power demand and energy requirements of various agricultural field operations in Malaysia. Ultimately, the obtained data would be processed, analysed, and transformed into agricultural machinery management standards for Malaysia. 
This paper describes the design, development, calibration and demonstration of a three-point auto-hitch dynamometer as apart of tractor's instrumentation system for agricultural database. Based on previous reviews, it was decided that a "U" shape main frame, category I and II threepoint auto-hitch dynamometer would be the best need of the department research. Such configurations would have application flexibility to most commercially available implements in Malaysia. The design of the extended octagonal ring transducer for the dynamometer was made based on ${ }^{24}$ design formulas. The system natural frequency and dynamic response are analysed to quantity for its dynamic measurements. The design of the three-point auto-hitch dynamometer would permit the use of the PTO torque transducer at the tractor PTO output for negative draught implement.

\section{MATERIALS AND METHODS}

\subsection{General description}

A three-point auto hitch dynamometer was designed and developed to measure the horizontal and vertical forces of the mounted implement on the Massey Ferguson 3060 tractor (Figure 1a). The design concept of the dynamometer was based on an instrumented inverted $\mathrm{U}$ frame assembly

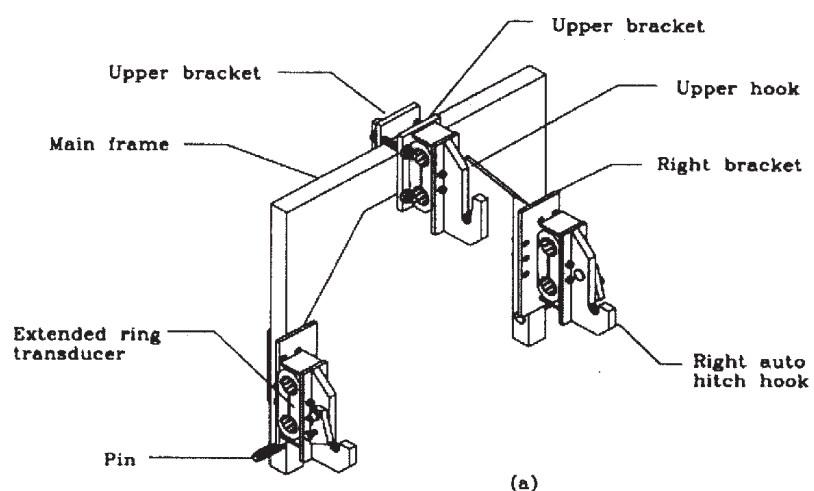

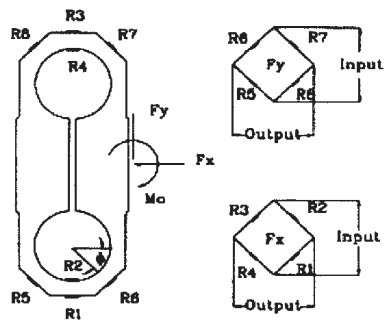

(b)

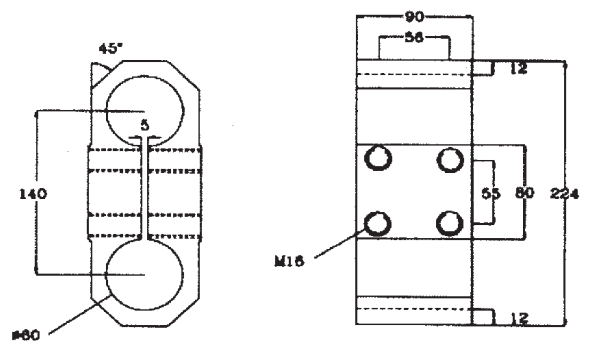

All dimensions in $\mathrm{mm}$

(c)

Figure 1: (a) Three-point auto hitch dynamometer. (b) Full bridge wirings diagrams for Fx and Fy different gauge arrangements. (c) Dimensions of the extended octagonal ring 
that was mounted between tractor links and implement. The design incorporated for both lower point hitch spread and mast height adjustments, and quick hitch capability in accordance with Category 1 and II three-point linkages system given in ASAE Standard S217.11 and S278.6 27-28. The force sensing elements were comprised of three steel extended octagonal ring transducers that were located between the inverted U frame and hook brackets. Eight KFG-5-120-C16L1M-2R Kyowa strain gauges were mounted on the extended octagonal ring transducer or EOR transducer at strain angle nodes of $90^{\circ}$ and $39^{\circ}$ to independently monitor strains that were proportional to the horizontal and vertical forces at the ring centre. Each extended octagonal ring has been designed for maximum horizontal and vertical forces of 25 and $10 \mathrm{kN}$, respectively. This complete three-point auto hitch dynamometer unit was $820 \mathrm{~mm}$ height and $870 \mathrm{~mm}$ wide. When mounted to the tractor it shifted the three point hitch location rearwards by $230 \mathrm{~mm}$ and added $134 \mathrm{~kg}$ weight to the tractor. The dynamometer has been designed to allow the passage of the tractor's PTO shaft for the installation of a torque transducer. The complete dynamometer unit was designed to measure maximum draft and maximum vertical force of 50 and $20 \mathrm{kN}$, respectively.

\subsection{Construction}

The main frame was a $\mathrm{U}$ frame shape welded steel structure, which was made from horizontal $125 \times 67 \times 5 \mathrm{~mm}$ and two vertical $67 \times 67 \times 5 \mathrm{~mm}$ sections. Two triangular plates were welded at the two frame corners to reinforce the frame. Each leg of the frame had a 12 bolthole bracket for the extended octagonal ring transducer and a pin for the tractor lower point linkage. Each lower hook bracket had 4-bolt-hole for the extended octagonal ring transducer and a simple plunger locking mechanism for the implement hitch pin. The upper hook bracket had a deep slot without spring mechanism to permit clearance for hitching or leveling requirements on the implement. Each hook bracket and extended octagonal ring transducer upon assembly could be bolted to the mounting of the $\mathrm{U}$ frame in accordance with Category 1 and II three-point linkage system requirements.

\subsubsection{Extended octagonal ring design}

The extended octagonal ring or EOR transducer offers a high ratio of sensitivity to stiffness, compactness, simple mounting, and provides simultaneous monitoring of the force components and the moment in the plane of these forces (Figure 1b). The principle of the EOR transducer follows that when orthogonal forces are applied to the ring, there are stress nodes, which are used as the basis for the independent force component measurements. The two force components need to be measured with minimum cross sensitivity.

The designed formulae of the EOR transducer were originally based on analytical equations derived by ${ }^{24}$ for plain extended ring. They used first approximations using strain energy techniques for the bending moments in the ring sections of plain extended ring transducer. McLaughlin ${ }^{25}$ presented a corrected equation for the bending moment in the upper ring by ${ }^{24}$, which had several typographic and sign errors. The expressions derived for the bending moment $\mathrm{M}_{\phi}$ at angle $\phi$ under the action of two orthogonal forces $\mathrm{F}_{\mathrm{X}}$ and $\mathrm{F}_{\mathrm{Y}}$ are given as follows: 


$$
\begin{aligned}
& M_{\phi}=\frac{F_{X} R}{2}\left(\frac{2}{\pi}-\sin \phi\right)+\frac{F_{Y} R}{2} \cos \phi+\frac{M_{0}\left[\left(2+\frac{R \pi}{2 L}\right)-\left(\frac{2 R}{L}+\pi\right) \sin \phi\right]}{\left(8+\frac{R \pi}{L}+\frac{2 L \pi}{R}\right)} \quad 0<\phi<\pi \\
& M_{\phi}=\frac{F_{X} R}{2}\left(\frac{2}{\pi}+\sin \phi\right)-\frac{F_{Y} R}{2} \cos \phi-\frac{M_{0}\left[\left(2+\frac{R \pi}{2 L}\right)-\left(\frac{2 R}{L}+\pi\right) \sin \phi\right]}{\left(8+\frac{R \pi}{L}+\frac{2 L \pi}{R}\right)} \quad \pi<\phi<2 \pi
\end{aligned}
$$

where $\mathrm{M}_{\mathrm{O}}$ is the applied external moment in $\mathrm{Nm}, \phi$ is the angle measured clockwise from the right side of the ring in radians, $\mathrm{R}$ is the mean radius of the ring measured to the centroidal axis of the cross section in $\mathrm{mm}$, and $\mathrm{L}$ is one half distance between ring centres in $\mathrm{mm}$. Equations 1 and 2 are equivalent to equations 43 and $44 \mathrm{in}^{24}$ with the errors in equation 44 being corrected.

The right and left sides of the EOR were restrained from rotation to give positive moments. The bending moment, and, therefore stress and strain at the surfaces of the ring section were zero in the computation of forces $F_{X}$ and $F_{Y}$ at angle $\phi$ of $90^{\circ}$ and $39.6^{\circ}$, respectively. The angles at which zero stress and strain occur are known as nodal angles, $\phi$. Therefore, if strain gauges are mounted in these positions and connected into Wheatstone bridge configurations, the gauges at angle $90^{\circ}$ will measure the force $\mathrm{F}_{X}$ independently of $\mathrm{F}_{Y}$ and those at $39.6^{\circ}$ will measure the force $F_{Y}$ independently of $F_{X}$. This is the essential principle of EOR transducers.

From elementary mechanics, using previous bending moment equations, the stress on the surface of the ring at the rectangular section of the EOR is given as:

$$
\sigma_{\phi}=\frac{6 M_{\phi}}{b t^{2}}
$$

where $\sigma_{\phi}$ is the strain due to node angle $\phi$ in $\mathrm{MPa}, \mathrm{M}_{\phi}$ is the moment at node angle $\phi$ in $\mathrm{Nm}$, $\mathrm{b}$ is the width of ring in $\mathrm{mm}$ and $\mathrm{t}$ is the thickness of the ring in $\mathrm{mm}$. The strain at any point on the surface of the ring could be calculated as:

$$
\varepsilon_{\phi}=\frac{6 M_{\phi}}{E b t^{2}}
$$

where $\varepsilon_{\phi}$ is the strain at node $\phi$ in $\mu$ Strain and $\mathrm{E}$ is the modulus of elasticity in GPa. Generally, the Massey Ferguson 3060 tractor with a net engine power of $64 \mathrm{~kW}$ has rated drawbar power of 75 to $81 \%$ of its net engine power in accordance with ASAE Standard D497.329. When this tractor was operated in its lowest gear combinations (i.e $2.3 \mathrm{~km} / \mathrm{hr}$ ), a maximum draft of 46.08 $\mathrm{kN}$ would be developed at it's three-point hitch. Again, this tractor size has hydraulic lift capacity on the three-point hitch of $310 \mathrm{~N} / \mathrm{kW}$ in accordance with ASAE Standard S349.2 $2^{30}$. Therefore, the maximum vertical force on the three-point hitch was estimated to be $20 \mathrm{kN}$. On this basis, loads of $50 \mathrm{kN}$ and $20 \mathrm{kN}$ were being matched to the design of the three-point auto hitch dynamometer system for maximum horizontal and vertical forces, respectively. In practice 
the two lower point linkages sustain most horizontal and vertical forces while the upper point hitch often gives negative draft and zero vertical force (i.e upper linkage is hinged). Accordingly, the design loads for each EOR had been taken as 25 and $10 \mathrm{kN}$ for maximum horizontal and vertical forces, respectively. Figure 2 shows the forces acting on the three-point auto-hitch dynamometer.

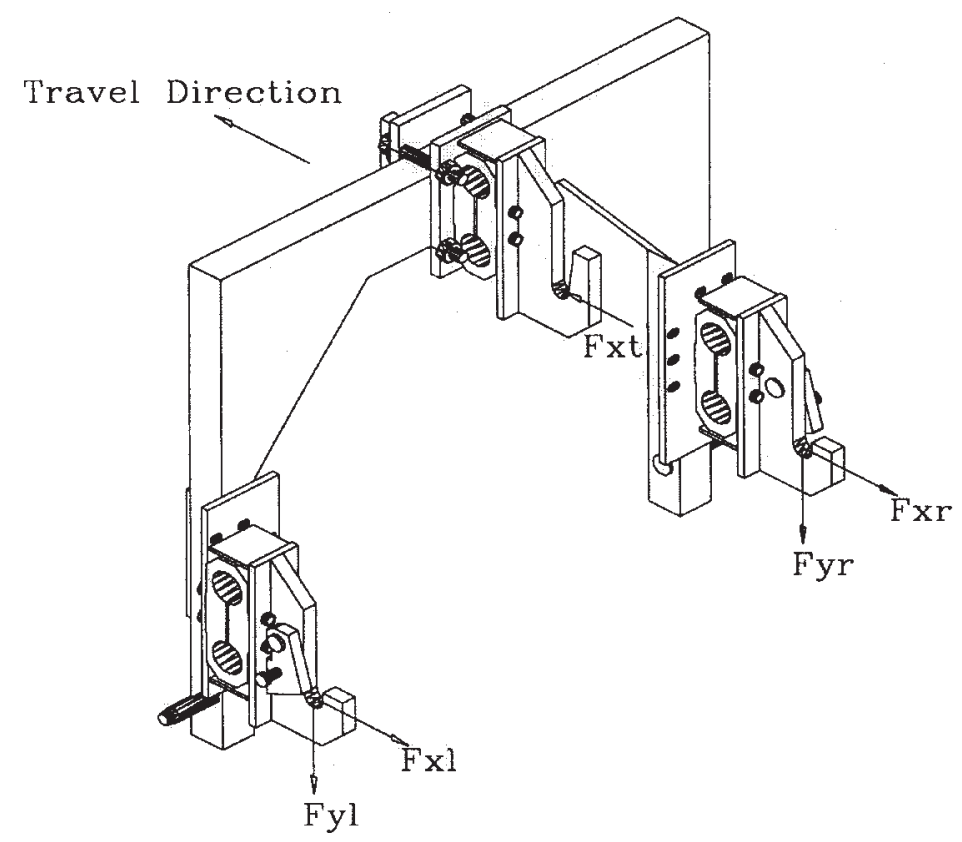

Figure 2: Forces acting on the three-point auto-hitch dynamometer

The material selected for the design of the EOR transducers was mild steel 1020 AISI having ultimate tensile strength of $320 \mathrm{MPa}$, yield stress of $180 \mathrm{MPa}$, and modulus of elasticity of 207 GPa which gave high strength and compactness to the transducer. This type of steel was chosen because of it is availability and easy machining. The selection of the mean radius, distance between ring centres and width of the EOR are dependent upon practical size constrains. Based on the authors past experiences on machinery fabrication and strain gauge mounting, dimensions of 30,70, and $90 \mathrm{~mm}$, for mean radius, distance between ring centres ring and width of the ring, respectively, were chosen for EOR design. Based on the EOR horizontal and vertical design loads and selected ring dimensions, the calculated bending moments at $90^{\circ}$ and $39.6^{\circ}$ or $\mathrm{M}_{90^{\circ}}$ and $\mathrm{M}_{39.6^{\circ}}$ are 0.319 and $0.145 \mathrm{kNm}$, respectively. The required ring thickness could be calculated by rearranging equation (3) as follows:

$$
t=\sqrt{\frac{6 M_{\phi}}{b \sigma}}
$$

When designing the ring it is necessary to select the mean radius and thickness for EOR so that the elastic limit is not exceeded. The ring thickness as calculated from equation 5 was $12 \mathrm{~mm}$. 
The ratio of mean radius to thickness was 3, which satisfied the requirement of thin ring theory that was employed in the design of the ring transducers $(R / t \geq 3)$. A slot of $5 \mathrm{~mm}$ width was made in the middle section of the EOR. Two plates of size $80 \times 90 \times 2 \mathrm{~mm}$ were located at both sides of EOR to provide for free rotation and deflections of the rings. Four thread holes were provided at both sides of EOR for mounting purposes. The final EOR dimensions specified are shown in Figure 1c. The ring maximum strain at the node angle of $90^{\circ}$ or $\varepsilon_{90^{\circ}}$ calculated from equation 4 was $713 \mu$ Strain and the maximum strain at node angle of $39.6^{\circ}$ or $\varepsilon_{39.6^{\circ}}$ was $324 \mu$ Strain.

\subsection{Strain nodes and strain gauge bridges}

The gauge locations were selected according to strain energy theory at node angles of $90^{\circ}$ and $39.6^{\circ}$ for the measurement of the horizontal force and vertical force, respectively. Accurate locations of the stress nodes and subsequent positioning of the strain gauges were crucial for the resulting sensitivity of the EOR transducer. The mounting method had to be considered in determining strain nodes to reduce the effects of cross sensitivity. The strain nodes for horizontal measurement were determined experimentally by mounting strain gauges at node angles of $40^{\circ}$, $39^{\circ}$ and $38^{\circ}$ close to the theoretical node for maximum strain while for vertical measurement at node angle of $90^{\circ}$ Results of the initial trials indicated that the cross sensitivity were negligible at node angles of $39^{\circ}$ and $90^{\circ}$ for measurement of horizontal and vertical force, respectively. The optimum strain nodes used on the EOR were $\phi_{90^{\circ}}$ and $\phi_{39}{ }^{\circ}$ for the measurement of horizontal force and vertical force, respectively.

The EOR transducer had eight gauges bonded at node angles $\phi_{39}{ }^{\circ}$ and $\phi_{90^{\circ}}$ and connected into two full bridges. The chosen strain gauges were of Kyowa KFG5120C16-L1M2R type with gauge resistance of resistance $120 \mathrm{Ohm}$ and gauge factor 2.1. The selected gauges were each provided with 1-meter length lead wires to avoid necessary soldering work. The mounted strain gauges at the respective nodes were wired to a constant current Wheatstone bridge configuration.

The calculated transducer sensitivity was expressed in terms of bridge output strain per unit force applied. Knowing the magnitude of the output nodes strains under design loads, the predicted sensitivities of the EOR channels were 32.40 and $28.52 \mu$ Strain/kN, respectively, for horizontal and vertical force.

\subsection{Strain gauge bridge configuration and installation}

A full bridge $2.5 \mathrm{~mA}$ constant current supply from the data acquisition system was used to excite the strain gauge bridges on the EOR transducer. The installation of the strain gauges was carried out after cleaning the EOR surfaces by fine silicon carbide abrasive with alcohol. The strain gauges were mounted at the respective strain nodes with use of epoxy adhesive. The SG280 protective coating was applied to protect the gauges. Each individual EOR transducer was covered by a bracket to provide mechanical protection for the installed strain gauges. 


\subsection{Horizontal and vertical displacements}

The important requirement of the EOR transducer is that the displacement under loading must be small. Hoag and Yoerger ${ }^{24}$ obtained the vertical and horizontal displacements of the plain extended ring through application of Castigliano's theorem. The expressions for maximum horizontal and vertical displacement for the lower and top EOR based on strain energy method are given below:

$$
\begin{aligned}
& \delta_{x l}=\frac{R^{2}}{E I}\left[F_{X} R\left(\frac{2}{\pi}-\frac{\pi}{4}\right)+\frac{M_{0}\left(4-\frac{\pi^{2}}{2}\right)}{\left(8+\frac{R \pi}{L}+\frac{2 L \pi}{R}\right)}\right] \\
& \delta_{x t}=\frac{R^{2}}{E I}\left[F_{X} R\left(\frac{2}{\pi}-\frac{\pi}{4}\right)-\frac{M_{0}\left(4-\frac{\pi^{2}}{2}\right)}{\left(8+\frac{R \pi}{L}+\frac{2 L \pi}{R}\right)}\right] \\
& \delta_{y l}=\delta_{y t}=\frac{R^{2}}{E I}\left[-\frac{F_{Y} R \pi}{4}+\frac{\frac{M_{0} R \pi}{L}\left(\frac{\pi}{2}-\frac{4}{\pi}\right)}{\left(8+\frac{R \pi}{L}+\frac{2 L \pi}{R}\right)}\right]
\end{aligned}
$$

The horizontal displacements for the designed EOR at the lower and top rings were found to be $2.76 \times 10^{-3}$ and $2.24 \times 10^{-3} \mathrm{~mm} / \mathrm{kN}$, while the vertical displacements for the designed EOR at the lower and top rings were found to be $16.9 \times 10^{-3}$ and $16.9 \times 10^{-3} \mathrm{~mm} / \mathrm{kN}$, respectively.

\subsection{Natural frequency and dynamic response}

The EOR transducers of the three-point auto hitch dynamometer cannot be isolated from imposed vibrations during field measurements. Consequently, the designed EOR transducer should be able to measure the dynamic mode response of horizontal and vertical force measurements. The dynamic response of the EOR transducer could be modelled as a single DOF of a spring-massdamper system. The transducer could be represented as a cantilever beam under a simple harmonic vibration that was excited by a fluctuating load at its free end. In order that the recorded force was not influenced of any vibration motion, the natural frequency of the transducer should be greater than the frequency of the exciting vibrations ${ }^{31}$. The natural frequency of the transducer could be expresses in terms of gravity acceleration and deflection and is given as:

$$
f_{n}=\frac{1}{2 \pi} \sqrt{\frac{g}{\delta}}
$$

where $\mathrm{f}$ is the natural frequency in $\mathrm{Hz}, \delta$ is the static deflection in $\mathrm{mm}$ and $\mathrm{g}$ is acceleration due to gravity in $\mathrm{m} / \mathrm{s}^{2}$. The calculated natural frequencies of the EOR the transducer for horizontal 
force measurement at the lower and top rings were 46 and $40 \mathrm{~Hz}$, while the natural frequencies for vertical force measurement at the lower and top rings were 44 and $44 \mathrm{~Hz}$.

\subsection{Calibration}

Extensive static calibration tests were carried out to determine the measurement linearity and accuracy between applied load with the measured output strain and accuracy between applied load with the measured load. The calibration of the three-point auto hitch dynamometer was measured by applying known forces and recording the electrical gain response. The unit was disassembled and each EOR transducer is calibrated individually. Each EOR was bolted to special bracket having point of application of forces similar to dynamometer's hooks. Both the EOR and the bracket are mounted on a loading frame. The loading frame was equipped with a hydraulic cylinder and a load cell was connected in series to the EOR transducer to measure the applied load. The load to EOR transducer was applied at $2 \mathrm{kN}$ intervals up to the capacity of $20 \mathrm{kN}$. DeCipher Plus program code was developed for the data acquisition system to scan and record the output strain of the mounted gauges on the EOR transducer. Each EOR transducer for the three-point auto hitch dynamometer was calibrated for horizontal and vertical loads and under both loading and unloading test modes. Each measurement at any applied load was repeated four times and each test at any loading mode was replicated four times. The cross sensitivity of the force components on the EOR transducer was also checked during the calibration test. The cross sensitivities were measured by applying a force in on direction and measuring the output of the bridge to measure the force in the orthogonal direction. Similar tests were also conducted to obtain the relationship between the measured load that was recorded by the data acquisition system and the applied load on the EOR transducer for the purpose of checking the measurement accuracy. This test was conducted only to the left EOR transducer of the threepoint auto hitch dynamometer for horizontal and vertical load under both loading modes. The involved test was similar as before.

\subsection{Statistical analysis}

During the calibration, each EOR transducer was subjected to 11 levels of applied loads and this involved test was replicated four times. A three way factorial statistical design that consisted of 3 EOR transducers, 2 modes of loading and 11 levels of applied load, and 4 replications were employed. For simplicity, the following linear additive model has been utilized:

$$
Y_{i j k l}=\mu+\alpha_{i}+\beta_{j}+\gamma_{k}++\left(\alpha \beta_{i j}+(\alpha \gamma)_{i k}+(\beta \gamma)_{j k}+(\alpha \beta \gamma)_{i j k}+\varepsilon_{i j k}\right.
$$

The General Linear Model procedure in PC SAS software package ${ }^{32}$ is employed to determine the relationship between output measured strain with applied load of calibrated EOR transducers

\subsection{Demonstration test}

A field test of the three-point auto hitch dynamometer on the tractor was conducted at the University's Farm (see Figure 3). The plot was from Serdang Series having sandy clay loam 


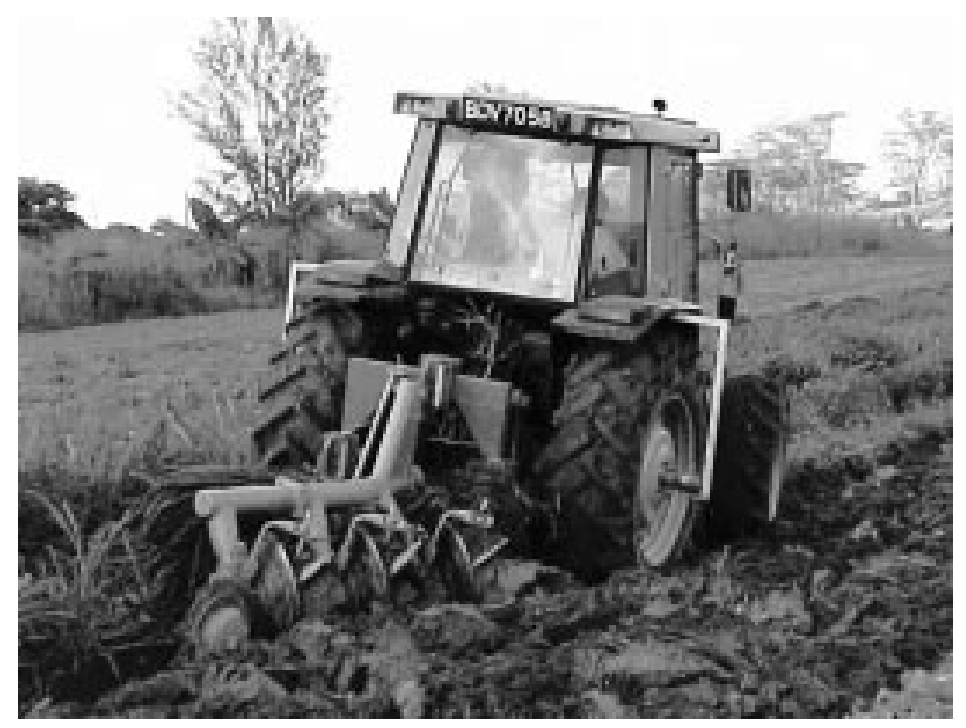

Figure 3 : Field demonstration test of three-point auto-hitch dynamometer

soil classification in accordance with the university's soil map. The tractor was equipped with data acquisition system and mounted 3-660, NARDI, BTDN500 disk plough was used in the test. The field trials were conducted to check on the effect of tractor forward speed at a tillage depth of $23 \mathrm{~cm}$ on the disk plough draft. At the end of the field test, the stored data in memory card was downloaded into hard disk of the host computer for analysis on the recorded draft measurements by the three-point auto-hitch dynamometer and its associated data acquisition system.

\section{RESULTS AND DISCUSSIONS}

The ANOVA calibration results for extended octagonal ring horizontal and vertical force are summarised in Table 2. The ANOVA for both horizontal and vertical forces show that all tested main affects and interactions with the exception of applied load had no significant $(\mathrm{P}>0.05)$ effect on measured strain output. There was no significant difference between the output strains of the three EOR transducers. Also there was no significant difference between modes of loading which implies no hysteresis effect between modes of loading on measured output strain. All these findings supported the use of one calibration equation for the horizontal and vertical force measurements.

The plotted calibration graph in Figures 4 and 5 show that applied load and measured output strain of the extended octagonal ring for horizontal and vertical forces measurements were highly correlated. The linearity equations for horizontal and vertical forces are expressed by:

$$
\begin{aligned}
& \mathrm{S}=25.186 \mathrm{~F}_{\mathrm{X}} \quad \text { with } \quad \mathrm{R}^{2}=0.9986 \\
& \mathrm{~S}=25.604 \mathrm{~F}_{\mathrm{Y}} \quad \text { with } \quad \mathrm{R}^{2}=0.9982
\end{aligned}
$$


Table 2 : ANOVA on the calibration data of extended octagonal ring transducer forces

\begin{tabular}{rlrrr}
\hline Force & Source of variation & \multicolumn{1}{c}{ SS } & \multicolumn{1}{c}{ MS } & F-value \\
\hline & Replication & 11369.7106 & 456.5702 & $19.24 \mathrm{NS}$ \\
& Octagonal & 562.0615 & 562.0615 & $23.69 \mathrm{NS}$ \\
Horizontal & Loading & 109.0845 & 109.0845 & $4.60 \mathrm{NS}$ \\
& Applied load & 4459853.3139 & 445985.3314 & $18795.53^{* *}$ \\
& Oct. $\times$ Load. & 0.1398 & 0.1398 & $0.01 \mathrm{NS}$ \\
& Oct. $\times$ A. Load & 309.4075 & 30.9408 & $1.30 \mathrm{NS}$ \\
& Load. $\times$ A. Load & 293.0863 & 29.3086 & $1.24 \mathrm{NS}$ \\
& Oct. $\times$ Load. $\times$ A. Load & 165.7322 & 16.5732 & $0.70 \mathrm{NS}$ \\
\hline Error & Replication & 3060.9456 & 23.7283 & $4.93 \mathrm{NS}$ \\
& Octagonal & 1431.6162 & 143.8721 & $8.58 \mathrm{NS}$ \\
& Loading & 501.0220 & 250.5110 & $1.52 \mathrm{NS}$ \\
& Applied load & 44.2358 & 44.2358 & $22205.63 * *$ \\
& Oct. $\times$ Load. & 6481709.2222 & 648170.9222 & $13.22 \mathrm{NS}$ \\
& Oct. $\times$ A. Load. & 771.7401 & 385.8701 & $1.26 \mathrm{NS}$
\end{tabular}

** Significant at $1 \%$ probability level

NS Not Significant

where, $S$ represents the measured output strain in $\mu$ Strain, $F_{X}$ for the applied horizontal force in $\mathrm{kN}$, and $\mathrm{F}_{\mathrm{Y}}$ for the applied vertical force in $\mathrm{kN}$. These two equations are used in the programming of Datataker 605 to read the measured strain output from the extended octagonal ring in $\mathrm{kN}$.

The measured strain gauge bridge sensitivities for the horizontal and vertical loadings of EOR transducers were 25.11 to $25.23 \mu \mathrm{Strain} / \mathrm{kN}$ and 25.42 to $25.79 \mu \mathrm{Strain} / \mathrm{kN}$, respectively. The

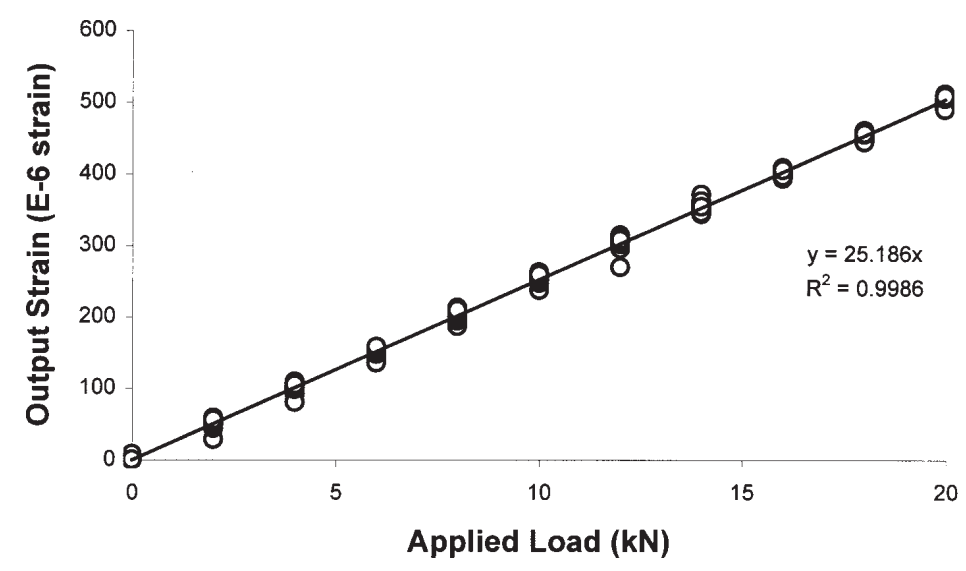

Figure 4 : Calibration curve for horizontal force of extended octagonal ring transducer 


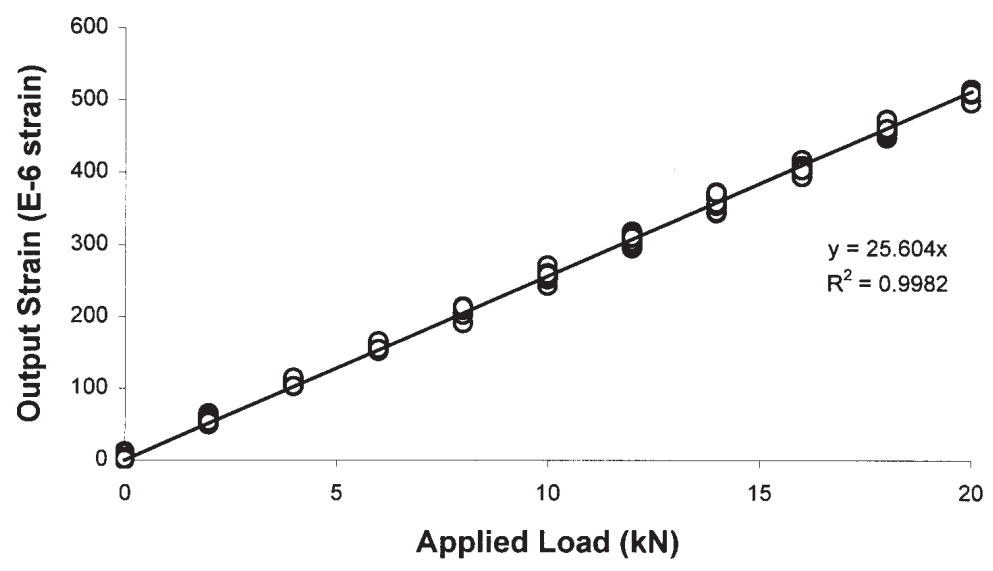

Figure 5 : Calibration curve for vertical force of extended octagonal ring transducer

measured sensitivities for horizontal loadings were $77.57 \%$ to $77.86 \%$ of the computed theoretical sensitivity (i.e. $32.40 \mu \mathrm{Strain} / \mathrm{kN}$ ) whereas the measured sensitivities for vertical loadings were $89.14 \%$ to $90.40 \%$ of the computed theoretical sensitivity $(28.52 \mu \mathrm{Strain} / \mathrm{kN})$. The degree of agreement between the measured sensitivities and computed magnitudes was acceptable. Generally, the measured sensitivities for the extended octagonal rings differ from those deduced theoretically for the plain extended rings ${ }^{19-22,25}$. Furthermore, the measured bridge sensitivities of the extended octagonal ring transducers were also due to the gain multiplier effect that was automatically set during autoranging by Datataker 605. A noise problem was encountered at the earlier stage of calibration. Extra sampling of signals input using a special command in DeCipher Plus software solved the problem. The cross sensitivity of the force components on the three point auto-hitch dynamometer were only considered for the left and right EOR transducers because they sustain horizontal and vertical forces and the upper EOR transducer sustains only the horizontal force. The observed cross sensitivity of the left EOR transducer was $1.2 \%$ and $2.0 \%$, respectively, for horizontal and vertical force, while for the right EOR transducer was $1.6 \%$ and $0.8 \%$, respectively, for horizontal and vertical force. Godwin ${ }^{20}$ reported cross sensitivities of $1.1 \%$ and $2.1 \%$ for draft and vertical force, respectively, when the vertical force gauges were mounted at $\phi_{34}{ }^{\circ}$ and the loading fixture was confined to central part of the boss section. Gu et al. ${ }^{33}$ reported varying cross sensitivity ranging from 0 to $4.0 \%$ depending on the loading direction and noted a substantial increase in cross sensitivity when the draft gauge mounted at $\phi_{45}{ }^{\circ}$ and the EOR was loaded along the entire length of the boss face. Generally, differences in machining of the EOR, locating of strain nodes, mounting of strain gauges, mounting of EOR and point of application of loads resulted in different measurement characteristics. These factors have to be considered in determining the strain nodes to reduce the effect of cross sensitivity.

Regression results between applied load and measured load of the extended octagonal ring for horizontal and vertical force showed a high degree of linearity. Their relationships are best expressed by the following equations: 


$$
\begin{array}{lll}
\mathrm{F}_{\mathrm{XM}}=1.0017 \mathrm{~F}_{\mathrm{X}} & \text { with } & \mathrm{R}^{2}=0.9999 \\
\mathrm{~F}_{\mathrm{YM}}=0.9988 \mathrm{~F}_{\mathrm{Y}} & \text { with } & \mathrm{R}^{2}=0.9999
\end{array}
$$

where $F_{X M}$ represents the measured output horizontal force in $\mathrm{kN}$ and FYM is the measured output horizontal force in $\mathrm{kN}$. The transducers were rated to give measurement accuracy within $0.17 \%$ and $0.12 \%$ range, respectively, for the horizontal and vertical force measurements. These factors were used for computing and documenting the measured output load of the transducers

The calculated horizontal displacements for the designed EOR at the lower and top rings by strain energy theory were $2.76 \times 10^{-3}$ and $2.24 \times 10^{-3} \mathrm{~mm} / \mathrm{kN}$, respectively, while the calculated vertical displacements for the designed EOR at the lower and top rings were $16.9 \times 10^{-3}$ and $16.9 \times 10^{-3} \mathrm{~mm} / \mathrm{kN}$, respectively. The estimated extended octagonal ring transducer natural frequencies from a single DOF of spring-mass-damper system were 44, 44, 44 and $140 \mathrm{~Hz}$. The working frequency of a typical tractor-implement system working in the field as indicated by ${ }^{34-35}$ was around $2 \mathrm{~Hz}$. The damping ratio or $\xi$ for the EOR transducer was assumed to be viscous in nature with a magnitude equal to 0.01 . With such damping ratio and frequency ratios or $\mathrm{f}_{\mathrm{s}} / \mathrm{f}_{\mathrm{n}}$ (i.e. ratios of tractor working frequency to the EOR transducer natural frequencies) being less than 0.1 , give a transmissibility magnitudes less than 1.01 which in turn results with horizontal and vertical force errors of no more than $1 \%$ of the excitation forces (Figure 6). Consequently, the conducted static calibration of transducers was acceptable for dynamic horizontal and vertical force measurement.

In the test of the three-point auto-hitch dynamometer, the data acquisition system was able to perform with only minor difficulties. All the available extended octagonal ring transducers in the system were able to function accurately throughout all trial runs. The Datataker 605 was successfully able to scan the available transducer signals without being affected by the field environments. The stored data in the memory card of the Datataker 605 was able to be downloaded and recovered into the hard disk of the computer at the end of trials. Figure 7 shows a sample

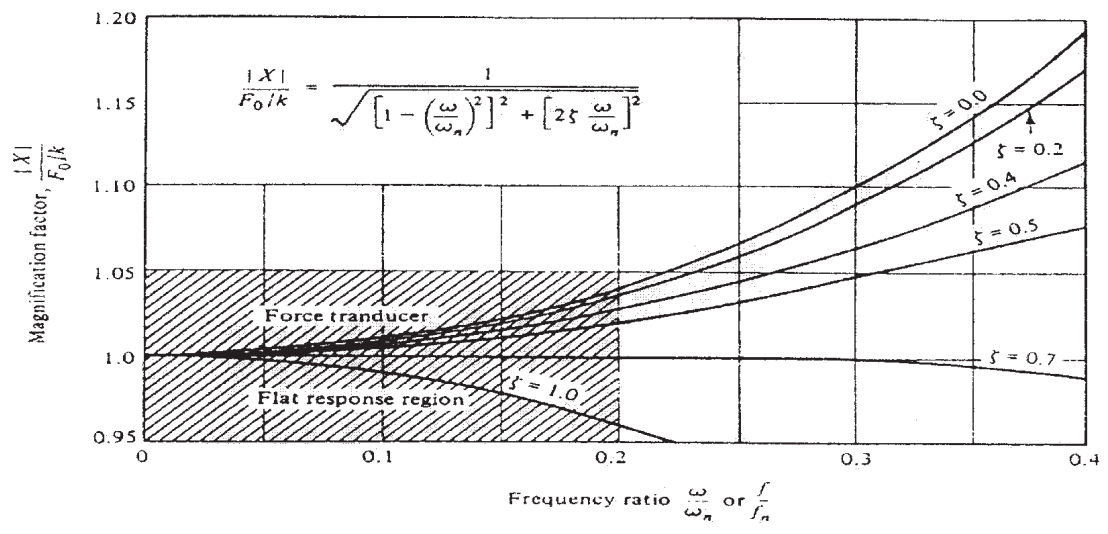

Source : James et al. [36]

Figure 6 : Typical dynamic response of force input at flat region 
data of the implement forces that was obtained as the results of operating the tractor with a disk plow at average operating speed of $4.63 \mathrm{~km} / \mathrm{h}$ and tillage depth of $23 \mathrm{~cm}$. The computed 95\% confidence interval for the measured horizontal and vertical force were found to be 15.90 $\pm 5.76 \mathrm{kN}$ and $2.14 \pm 1.90 \mathrm{kN}$, respectively. The variations on the measured horizontal and vertical forces with time were due to the varying soil properties in the heterogeneous field. Table 3 gives the summary of horizontal and vertical forces measured with the three-point auto hitch dynamometer for disk plow operations at four selected tractor gears. Most of the measured field workable loads were likely to be in the range of $30 \%$ of the dynamometer horizontal and vertical design loads. Using the rule that for transducer applications the stress should not be greater than $30 \%$ of the yield stress, the estimated horizontal and vertical design load for the dynamometer were acceptable. In other words this dynamometer has a safety factor of more than three to provide for accidental overloads in practice. These field data shows that the dynamometer has adequate sensitivity and sufficient strength for the fieldwork. Conclusively, the field trials had fulfilled the objective for running a quick check on the data acquisition system for actual field measurements.

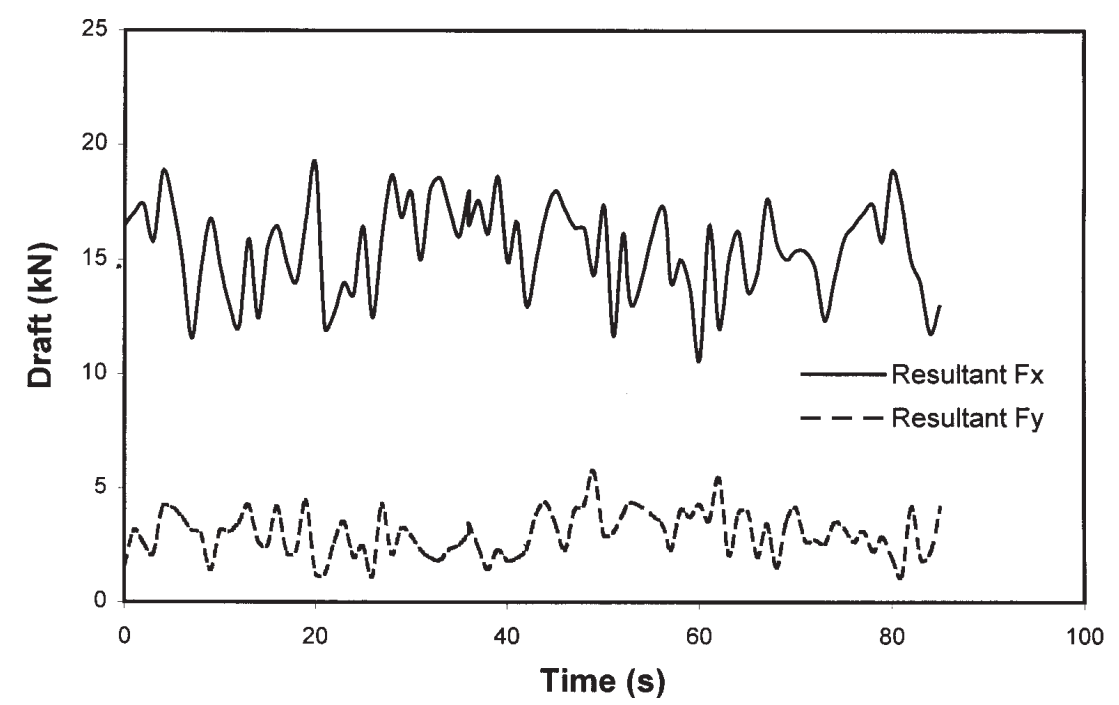

Figure 7: Horizontal and vertical force measurement at three-point hitch

Table 3 : Horizontal and vertical forces exerted by disk plough at selected tractor gears as measured with 3-point dynamometer

\begin{tabular}{ccccccccc}
\hline \multirow{2}{*}{ Gear } & \multicolumn{2}{c}{ Speed $(\mathrm{km} / \mathrm{h})$} & & \multicolumn{2}{c}{ Horizontal force $(\mathrm{kN})$} & & \multicolumn{2}{c}{ Vertical force $(\mathrm{kN})$} \\
\cline { 2 - 3 } & Average & S.D & & Average & S.D & & Average & S.D \\
\hline A4 Low & 1.90 & 0.07 & & 11.32 & 2.17 & & 2.67 & 1.05 \\
B2 Low & 2.71 & 0.18 & & 12.67 & 1.85 & & 3.15 & 1.22 \\
B4 Low & 3.71 & 0.17 & & 12.94 & 2.25 & & 2.56 & 1.00 \\
A2 High & 4.63 & 0.14 & & 15.90 & 2.76 & & 2.14 & 0.91 \\
\hline
\end{tabular}




\section{CONCLUSIONS}

A three-point auto-hitch dynamometer has been successfully designed, developed, calibrated and demonstrated to measure horizontal and vertical forces existing at the three-point linkage of the Massey Ferguson 3060 tractor for mounted implements having hitch category I and II. The design concept of the dynamometer was based on an inverted ( $U$ frame) assembly equipped with three extended octagonal ring transducers that are mounted between the tractor linkage and implement. Each transducer was designed for a maximum horizontal and vertical force of 25 $\mathrm{kN}$ and $10 \mathrm{kN}$, respectively, while the whole dynamometer was designed for forces of $50 \mathrm{kN}$ and $20 \mathrm{kN}$. Static calibration tests on all of the designed transducers showed excellent measurement linearity between applied load and output strain and excellent measurement accuracy between applied load and measured load (correlation coefficient close to 0.99). The mean measured strain gauge bridge sensitivities for the horizontal and vertical loading were $25.19 \mu \mathrm{Strain} / \mathrm{kN}$ and $25.60 \mu \mathrm{Strain} / \mathrm{kN}$, respectively. Both mean measured sensitivities were $77.75 \%$ and $89.77 \%$, respectively, of the computed theoretical sensitivities (i.e. 32.40 and $28.52 \mu \mathrm{Strain} / \mathrm{kN}$ ). Furthermore, all transducers have been designed with good stiffness as indicated by their small displacements at the design loads. The natural frequencies of the transducers were estimated from a single DOF spring-mass-damper. The transducers dynamic response was fairly acceptable for dynamic load measurements at the tractor's three point hitch. Field trials on the dynamometer and data acquisition system were satisfactory. All transducers were able to scanned and recorded by the datalogger under the field environments. The stored data in the memory card from the field trials was able to be down loaded into the hard disk of the host computer.

\section{ACKNOWLEDGEMENTS}

This research project is classified under RM7 IRPA Project No. 01-02-04. The authors are very grateful to the Ministry of Science, Technology and the Environment of Malaysia for granting the fund for this research project.

\section{REFERENCES}

1. Reece, A.R. (1961), J. Agric. Engng Res, vol. 6, no. 1, pp. 45-50.

2. Morling, R.W. (1963), Soil force analysis as applied to tillage equipment. ASAE Paper No. 63-149, 1963.

3. Scholtz, D.C. (1964), J. Agric. Engng Res., vol. 9, no.2, pp.252-258 Luth, H.T., Floyd, V.G. and Heise, R.P. (1978), Evaluating energy requirements of machines in the field. ASAE Paper No. 78-1538.

4. Luth, H.T., Floyd, V.G. and Heise, R.P. (1978), Evaluating energy requirements of machines in the field. ASAE Paper No. 78-1538.

5. Upadhyaya, S.K., Kemble, L.J. , N.E. Collins, F.A. Camargo and Jr. (1985), Transactions of the ASAE, vol. 28, no.1, pp. 40-46,

6. Scholtz, D.C. (1966), J. Agric. Engng Res., vol. 11, no. 1, pp. 33-37, 1966.

7. Johnson, C.E. and Voorhees, W.B.(1979), Transactions of the ASAE, vol. 22, no.2, pp. 226-228, 232. 
8. Smith, L.A. and Barker, G.L. (1982), Transactions of the ASAE, vol. 25, no.5, pp.15561559.

9. Chung, Y.G., Marley, S.J. and Buchele, W.F. (1983), Equipment to monitor field energy requirements, ASAE Paper No. 83-1035.

10. Reid, J.T., Carter, L.M. and Clark, R.L.(1985), Transactions of the ASAE ,vol.28, no. 1, pp. 89-93.

11. Chaplin, J., Lueders, M. and Zhao, Y. (1987), Applied Engineering in Agriculture, vol. 3, no.1, pp. 1047-1053.

12. Garner, T.H., Dodd, R.B., Wolf, D. and Peiper, U.M. (1988), Transaction of the ASAE, vol. 31, no. 4, pp. 1047-1053.

13. Jenane, C., Tabesch, F., Spruth, H. and Chaplin, J. (1989), A three-point hitch dynamometer for tillage research in Morocco. In Land and Water Use, ed. Dodd and Grace. Rotterdam: Balkema, pp. 3073-3077.

14. Palmer, A.L. (1992), J. Agric. Engng Res., vol. 52, pp.157-167.

15. McLaughlin, N.B., Heslop, L.C., Buckly, D.J., Amour, G.R., Complon, B.A., Jones, A.M. and Van Bodegom, P. (1993), Transactions of the ASAE, vol. 36, no.2, pp. 265273.

16. Cook, N.H., Lowen, E.G. and Shaw, M.C. (1954), American Machinist, vol. 98, no. 10, pp. $125-130$.

17. Lowen, E.G. and Cook, N.G. (1956), Experimental Stress Analysis,vol. 13, no.2, pp. 5762.

18. Cook N.H. and Rabinowicz, E. (1963), Physical measurement and analysis. New York: Addison-Wesly. pp 160-164.

19. O’Dogherty, M.J.(1975), J. Agric. Engng Res., vol. 10, pp. 333-345.

20. Godwin, R.J.(1975), J. Agric. Engng Res., vol. 10, pp. 347-352.

21. Thakur, T.C and Godwin, R.J. (1988), Agricultural Mechanisation in Asia, Africa and Latin America., vol. 19, no.3, pp. 23-28.

22. Godwin, R.J., Reynolds, A.J., O'Dogherty, M.J. and Al-Ghazal, A. A. (1993), J. Agric. Engng Res., vol. 55, pp.189-205.

23 O’Dogherty, M.J.(1996), J. Agric. Engng Res, vol. 63, pp. 9-18.

24. Hoag, D.L. and Yoerger, R.R.(1975), Transactions of the ASAE,vol. 19, pp. 995-1000.

25. McLaughlin, N.B. (1996), Transactions of the ASAE, vol. 39, no.2, pp. 443-444.

26. Kheiralla, A.F. and Azmi Yahya (2001), Pertanika J. Sci. \& Technol, vol. 9, no. 2, pp. 51-67.

27. ASAE Standards (1997), ASAE S 217.11: Three-point free-link attachment for hitching implements to agricultural wheel tractors. In: Hahn, R.H., Purschwitz, M.A., and Rosentreter, E.E. (eds.), ASAE Standards (1997), 44th edition, ASAE, St. Joseph, MI, pp. 88-91.

28. ASAE Standards (1997), ASAE S278.6: Attachment of implements to agricultural wheel tractors equipped with attaching coupler. In: Hahn, R.H., Purschwitz, M.A., and Rosentreter, E.E. (eds.), ASAE Standards (1997), 44th edition, ASAE, St. Joseph, MI, pp. 105-107. 
29. ASAE Standards (1997), ASAE D497.3, Agricultural machinery management data. In: Hahn, R.H., Purschwitz, M.A., and Rosentreter, E.E. (eds.), ASAE Standards (1997), 44th edition, ASAE, St. Joseph, MI, pp. 363-370.

30. ASAE Standards (1997), ASAE S349.2: Standard test procedure for measuring hydraulic lift capacity on agricultural tractors equipped with 3-point hitch In: Hahn, R.H., Purschwitz, M.A., and Rosentreter, E.E. (eds.), ASAE Standards (1997), 44th edition, ASAE, St. Joseph, MI, pp. 200-201, 1997.

31. Timoshenko, S., Young, D. H. and Weaver, W. (1990), JR. Vibration problems in engineering. 5th ed. New York: John Wiley and Sons.

32. SAS User's Guide (1996): Statistics. Statistical Analysis System Inc., NC.

33. Gu, Y., Kushwaha, R.L. and Zeorb, G.C. (1993), Transactions of the ASAE , vol. 36, no.6, pp.1967 -1972.

34. Claar, P.W., Sheth, P.N., Buchele, W.F. and Marley, S.J. (1982), Transactions of the ASAE.vol. 25, no.3., 590-594.

35. Erickson, L.R. and Larsen, W.E. (1983), Transactions of the ASAE., vol. 26, no.6, pp. 1346-1351.

36. James, M.L., Smith, G.M., Wolford, J.C. and Whaley, P.W. (1989), Vibration of mechanical and structural system with microcomputer applications. 1st ed. New York: Harper \& Row. 